\title{
Urban Noise in a Metropolitan Towns
}

\author{
Lakavath Ravinder*, Mesfin Getahun Belachew \\ Department of Construction Technology and Management, Wolaita Sodo University, Wolaita Sodo, Ethiopia \\ Email: Iravinderiitm@gmail.com, mgmango1314@yahoo.com
}

Received 16 September 2014; revised 15 October 2014; accepted 13 November 2014

Copyright @ 2014 by authors and Scientific Research Publishing Inc.

This work is licensed under the Creative Commons Attribution International License (CC BY).

http://creativecommons.org/licenses/by/4.0/

(c) (;) Open Access

\section{Abstract}

This study is aimed at bringing out the salient aspects of urban noise and its study and control aspects, at different location of a metropolitans town. Field measurements at different points of times a day have also been recorded at a number of high-traffic-intensity locations on main roads of towns. The data obtained are analyzed using SPSS package for calculation through ANOVA technique and the findings of these studies have been recorded. The variation of SPL considering the time of the day has been studied and illustrated through graphical plots. It shows that the peak early morning max sound pressure levels observed over the recommended limiting value. In some places, the low frequency noise predominates in the early morning hours, noise levels are significant among and within the 15 groups. The variation of sound pressure (Maximum, Minimum and $L$ equivalent readings) levels as shown in the graphical plots, the Maximum and $L$ equivalent levels exceeded the recommended noise level. Important conclusions of this work have been drawn subsequently.

\section{Keywords}

Noise Pollution, Noise Effects, Noise Control, SPSS Package, ANOVA Technique, Sound Pressure Level, Decibel-Sound, Sound When A-Weighted

\section{Introduction}

Noise is generally considered to be unwanted sound and sound can be considered unwanted due to reasons of volume, type of noise, the time of day, or any factor making sound unpleasant or annoying [1]. As this is often subjective, noise pollution can be controversial. Noise pollution impacts upon health and wellbeing by causing disturbances that create poor quality environments. Noise pollution in residential environments can cause physical and mental health deterioration [2] [3]. In the workplace and educational environments, these symptoms can accompany reduced productivity and quality of work.

\footnotetext{
*Corresponding author.
} 
1. Noise pollution is the disturbing or excessive noise that may harm the activity or balance of human or animal life. The source of most outdoor noise worldwide is mainly caused by machines and transportation system, motor vehicles, aircraft, and trains. Outdoor noise is summarized by the word environmental noise. Due to poor urban planning may give rise to noise pollution, since side-by-side industrial and residential building can result in noise pollution in the residential areas [4] [5].

2. Indoor noise can be caused by machines, building activities, and music performances, especially in some workplaces. There is no great difference whether noise-induced hearing loss is brought about by outside (e.g. trains) or inside (e.g. music) noise [4].

3. High noise levels can contribute to cardiovascular effects in humans, a rise in blood pressure, and in increase in stress and vasoconstriction, and an increased incidence of coronary artery disease. In animals, noise can increase the risk of death by altering predator or prey detection and avoidance, interfere with reproduction and navigation, and contribute to permanent hearing loss.

\subsection{Noise Control}

Noise control or noise mitigation is a set of strategies to reduce noise pollution or to reduce the impact of that noise, whether outdoors or indoors. The main areas of noise mitigation or abatement are: transportation noise control, architectural design, urban planning through zoning codes, [1] and occupational noise control. Roadway noise and aircraft noise are the most pervasive sources of environmental noise worldwide, and little change has been affected in source control in these areas since the start of the problem, a possible exception being the development of hybrid and electric vehicles. Social activities may generate noise levels that consistently affect the health of populations residing in or occupying areas, both indoor and outdoor, near entertainment venues that feature amplified sounds and music that present significant challenges for effective noise mitigation strategies.

Multiple techniques have been developed to address interior sound levels, many of which are encouraged by local building codes; in the best case of project designs, planners are encouraged to work with design engineers to examine trade-offs of roadway design and architectural design. These techniques include design of exterior walls, party walls, and floor and ceiling assemblies; moreover, there are a host of specialized means for damping reverberation from special-purpose rooms such as auditoria, concert halls, entertainment and social venues, dining areas, audio recording rooms, and meeting rooms.

Many of these techniques rely upon materials science applications of constructing sound baffles or using sound-absorbing liners for interior spaces. Industrial noise control is really a subset of interior architectural control of noise, with emphasis upon specific methods of sound isolation from industrial machinery and for protection of workers at their task stations.

Noise control techniques include the following:

- Sound insulation: prevent the transmission of noise by the introduction of a mass barrier. Common materials have high-density properties such as brick, thick glass, concrete, metal etc.

- Sound absorption: a porous material which acts as a "noise sponge" by converting the sound energy into heat within the material. Common sound absorption materials include decoupled lead-based tiles, open cell foams and fiberglass

- Vibration damping: applicable for large vibrating surfaces. The damping mechanism works by extracting the vibration energy from the thin sheet and dissipating it as heat. A common material is sound deadened steel.

- Vibration isolation: prevents transmission of vibration energy from a source to a receiver by introducing a flexible element or a physical break. Common vibration isolators are springs, rubber mounts, cork etc.

\subsection{Literature Review}

The noise levels can be reduced through redistributing the traffic flows. It has advantageous to concentrate the traffic to a few streets and to locate these as for from receiver as possible [5]. The absorptive material can be used to reduce the noise levels as well.

The strategic assessment of environmental noise, US has introduced on indicator $\mathrm{L}_{\mathrm{den}}$, calculated according to their environmental noise directive [6], $\mathrm{L}_{\mathrm{Aeq}}$. With a $5 \mathrm{~dB}$ penalty for evening noise and $10 \mathrm{~dB}$ penalty for nighttime noise levels. 
The reverberation time of room is focused by [7]. The measurement of the reverberation time has been carried out, the RT measured is quite similar, and decreases fairly uniformly as the frequency increases. Moreover, in each frequency band the greater the volume of the room, the greater the RT observed.

The design of the barrier shape 1) gives a better sound absorption at the total frequencies of interest 2) protects the inside absorption layer from deterioration due to harsh weather [8] [9]. For a lightly damped thinwalled barrier, the absorption treatment not only absorbs acoustical energy but also damps the barrier structure resulting in a negligible energy transmission. The results demonstrated that for total noises the proposed barrier is more effective than reflecting and absorbent barriers [10].

The Planning and Development Regulations [11] [12] provide planning exemptions for renewable technologies for commercial, public, industrial and agricultural buildings where noise levels do not exceed $43 \mathrm{~dB}(\mathrm{~A})$, during normal operations as measured from the nearest party boundary.

\subsection{Noise Pollution}

Within the last few years, concern about the protection of the environment has grown rapidly as it has become generally recognized that steady rise in pollution of all kinds cannot be allowed to continue indefinitely. The acoustic environment has likewise suffered from the increase in use and power of the machines in the workplace, increasing road traffic, larger aircrafts etc. To combat this, many countries have introduced legislation making it a legal requirement to measure noise levels to reduce noise from vehicles at the source and maintain acceptable noise levels in factories to prevent hearing loss. India has emerged as fast developing country resulting in an increase in activity of the workforce. In 1989, Central Pollution Control Board (CPCB) [13], promulgated the Ambient Air Quality Standards for Noise, hereby establishing the noise limits for residential, commercial and silence zone areas. For assessing the urban noise problem and suggesting the mitigation measure, it is imperative that accurate data be obtained/measured of the noise levels at different locations at different times of the day.

\section{Noise Emission Characteristics of Individual Vehicles}

Traffic noise results from the collective contribution of the noise produced by the individual motor vehicles. The noise generated by single vehicle depends primarily upon the following [14] [15]:

a) Type and class of the vehicle (i.e. cars, trucks, buses, motor cycles etc.).

b) The quantity and quality of the noise control measures used in the vehicle design.

c) The mechanical condition of in-service vehicles (e.g. wearing of components, condition of exhaust silencer, engine tuning etc.).

d) The mode of operation of the vehicle (e.g. Steady speed, acceleration/deceleration, gear setting).

e) The propagation conditions (e.g. Reflecting obstacles, screening) to quantify the peak levels generated by passing vehicles, the following two main methods have been developed:

1. Standard acceleration test, as described in ISO recommendation ISO R 362 and in BS 3425; this requires and open test area, standardized specifically for rating vehicle noise.

2. Road side measurements where a wider grouping of vehicles is used and measurements of peak noise levels of individual vehicles are taken in a real traffic situation.

\subsection{Sources of Vehicle Noise}

The sources of vehicle noise have been identified as the power unit (engine, air inlet and exhaust), cooling fan, transmission (gear box and rear axle), rolling noise (aerodynamic and tyre/road surface), bakes, body rattles and load. In general sources related to the power unit and transmission upto the lay shaft are referred to as power train noise and all other sources are termed rolling noise [9].

The relative importance of these sources depends on the type of the vehicle and the operating condition. With light vehicles the engines is dominant at low road speed order or higher than power train noise. However with heavy diesel engine Lorries the engines, exhaust and cooling fan noise are the dominant sources under most operating conditions although the noise of the tyres rolling on the road surface can be noticeable at high speeds, particularly with tyres having pronounced transverse ribs.

The noise for typical light vehicles (less than 1.5 times) as well as heavy vehicles increases at a rate of about 9 dBA per doubling of speed. At higher speeds power train noise, and hence total noise, increases at a similar rate, 
with the rolling noise remaining approximately the same. At lower speeds in urban areas where lower gears are used, power train noise tends to be independent of road speed and hence rolling noise becomes insignificant as speed falls. A comparison of these parameters has been tabulated in Table 1.

The relative magnitude of noise from separate sources for a vehicle operating in a top gear at a steady speed of approximately $50 \mathrm{~km} / \mathrm{h}$ is given Table 2 .

Mechanical noise can originate from many different sources of an engine and can be much more difficult to locate and quantify than combustion noise. The most common sources of mechanical noise are piston slap, timing drive noise, bearing forces and rotations, and other including value train impacts, fuel injection pump, etc. The main sources of tyre noise are aerodynamic noise, air pumping and tyre vibration. The most efficient methods of vehicle noise reduction should be achieved in early stages of vehicle design and during proto type development of the vehicles and engines. Further improvements such as in tyre surface noise can be achieved by proper design of the road surface.

\subsection{Road Vehicle Noise Emission Legislation}

The legislative constrains on today's automotive industry are considerable. In USA the Society of Automotive Engines (SAE) makes recommendations in the form of standards for the noise testing of a variety of vehicles, for example SAE J986 for passenger car and light trucks. SAE J968 similar to the ISO R362 procedure, distance of $15 \mathrm{~m}$ truck length and microphone measuring distance of $15 \mathrm{~m}$ [12]. There are detailed differences in the use of gears and the interpretation of results but basically, the test is still a low gear, wide open throttle test, measuring the maximum sound pressure level on a sound level meter mid way along the truck. Noise regulation in USA exist for two categories of vehicles, namely,

1) Medium and heavy trucks (gross weight $>4500 \mathrm{~kg}$ ).

2) Motor cycle and motor-cycle exhaust systems. The road vehicle noise limits in USA are shown Table 3. And the nominal limits for light vehicle in USA are given Table 4.

\section{Factors Affecting Traffic Noise}

The generations of traffic noise various according to the volume of traffic, the type of vehicles comprising the traffic stream and their mode of operation [16] [17]. Once the noise has been generated, the conditions which are affected by geometrical considerations obstacles and reflection affects from buildings and other surfaces.

\subsection{Factors Affecting Generation of Traffic Noise}

The levels of noise generated y road traffic depend mainly upon the type of vehicle flow, the volume of traffic, the speed and composition of the traffic, the road gradient and the type of road surface. The type of vehicle flow is 1) Free flowing and 2) Interrupted traffic. As the flow rate of traffic increases, the traffic, Leq also increases upto saturated condition, beyond which, the effect of reducing vehicle speed on noise predominates. Whether

Table 1. Comparison of rolling and power train noise levels.

\begin{tabular}{ccccc}
\hline Road speed $(\mathrm{Km} / \mathrm{h})$ & Vehicle class & Rolling noise dBA & Power train noise dBA & Total noise dBA \\
\hline \multirow{2}{*}{20} & Heavy & 61 & 78 & 78 \\
& Light & 58 & 64 & 65 \\
\multirow{2}{*}{80} & Heavy & 79 & 85 & 76 \\
& Light & 76 & 74 & 78 \\
\hline
\end{tabular}

Table 2. Typical noise levels of sources (dB (A) at $7.5 \mathrm{~m})$.

\begin{tabular}{|c|c|c|c|c|c|}
\hline Type of vehicle & Exhaust & Engine and transmission & Cooling fan & Inlet & Rolling \\
\hline $\begin{array}{l}\text { Commercial } \\
\text { Tractor unit }\end{array}$ & 82 & 90 & 78 & 70 & 70 \\
\hline Passenger car & 74 & 84 & 65 & 65 & 68 \\
\hline
\end{tabular}


Table 3. Road vehicle noise limits-dB (A), USA.

\begin{tabular}{ccc}
\hline Vehicle description & Before (1/1/86) & After $(1 / 1 / 86)$ \\
\hline Medium and heavy trucks & 83 & 80 \\
$>100,001$ b (4500 kg) GVW & 83 & 80 \\
Motor cycles Street motor cycles & 70 & No charge \\
Moped off-road motor cycle & 83 & 80 \\
$<170$ cc & 86 & 82 \\
\hline
\end{tabular}

Table 4. USA state noise limits for passenger cars/Light trucks.

\begin{tabular}{ccc}
\hline Location (state) & Vehicle weight (lb) & 1984 limit dB (A)@ $50 \mathrm{ft}$ \\
\hline California & $\leq 10,000$ & 80 \\
Colorado & $<6000$ & 84 \\
Mayland & $\leq 10,000$ & 80 \\
Nevada & $<6000$ & 84 \\
Florida & $\leq 10,000$ & 80 \\
Washington & $\leq 10,000$ & 80 \\
\hline
\end{tabular}

considering hourly values of Leq, $\mathrm{L}_{10}$ etc., as a function of mean hourly flow or longer term averages of these indices, it is generally accepted that over a wide range of traffic flows the variation of these indices with vehicle flow, $\mathrm{Q}$, can be adequately represented by a logarithmic relation of the form $\mathrm{L}=\mathrm{Clog}_{10} \mathrm{Q}$.

\subsection{Factor Affecting Propagation of Traffic Noise}

The propagation of traffic noise is influenced by a number of factors. These include the attenuation due to distance, the interaction of the propagating wave with the ground surface, the barriers, the effect of vegetation, and, for long distance propagation, the effect of varying weather conditions.

\subsection{Attenuation Due to Distance}

Noise radiated from an Omni-directional point source into a free space attenuates according to the inverse square law, i.e. the acoustic field decreases as 20logd decibels. Although road vehicles are neither Omni-directional nor point sources a similar attenuation function can be obtained in the far field for isolated vehicle noise propagating over a hard reflecting ground surface. Consequently, provided these conditions are observed, in practice the peak noise levels from individual vehicles will attenuate by approximately $6 \mathrm{dBA}$ per doubling of distance from the vehicles on a road segment approaches the distance separating the receiver from the traffic lane. As the flow increases further, the geometric spreading approaches that of a line source such that, theoretically, the acoustic field attenuates as $10 \log _{10} \mathrm{~d}$ decibels.

\subsection{Screens and Diffraction of Traffic Noise}

When an obstacle intercepts the line of sight from the source to a receiver, the noise at the receiver is reduced. The amount of screening provided caries according to the amount of sound energy that is diffracted over the top of the barrier. For traffic noise problems, the sound energy transmitted through a roadside screen can generally be neglected since the transmission loss through most barrier material is much higher than the potential screening performance determined by the barrier geometry. For example, a barrier material with a surface mass of 20 $\mathrm{kg} / \mathrm{m}^{2}$ will generally provide a transmission loss of more than $20 \mathrm{~dB}$. This of course, assumes that there are no haps in the structure.

\subsection{Sound Attenuation by Vegetation}

Trees, brushes and plants are of great value in improving the aesthetics of road environment However; the noise attenuation provided by vegetation is generally overestimated. Vegetation may affect the propagation of low-fre- 
quency sound by ground absorption which can be enhanced in wooden areas because of the high porosity of the ground resulting from tree roots and fallen leaves, etc. High-frequency propagation is affected be scattering by tree trucks, braches and partly by leaf absorption.

\section{Controlling Traffic Noise Impact}

There are two main methods of controlling the impact of traffic noise on communities. One approach is to attempt to reduce noise at its source by the design of quieter vehicle and quieter road surface. The second approach involves attempts to limit the spread of noise, once generated, by considering such factors as the traffic flow, the road design and alignment, the use of noise screens and barriers and by planning the land use along-side the road to minimize disturbance to sensitive areas.

A further technique involves the insulation of buildings to minimize the incursion of noise into sensitive areas within the building fabric itself.

\section{Traffic Measures}

The most obvious way to refuse traffic noise is to move the traffic away from the noise-sensitive section of the road. Halving the traffic flow, for example, will generally lead to reductions in traffic noise $\mathrm{L}_{10}$ and Leq levels of the order of $3 \mathrm{dBA}$. However, closing road sections from all traffic can present problems of access.

The reduction of traffic speed is one of the most effective traffic measures controlling traffic noise levels. On high speed roads, halving average vehicle speed could lead to Leq noise level reductions of between 5 to $6 \mathrm{dBA}$.

\section{Noise Estimation Studies Carried out}

As part of the study, noise survey is conducted at 15 high traffic-intensity locations in Chennai city. The locations are selected to include place where free flow of traffic exists and no congestion occurs. At each location, the Noise Level measurements are taken at 15 min intervals from $0600 \mathrm{~h}-1900 \mathrm{~h}$ on weekdays, to provide a broad database. At each place, in each time slot, the maximum and minimum sound levels and Leq are noted with A-Weighted setting of the sound level meter, and in each one third octave band frequency with linear setting of the instrument. The data thus collected for two locations is tabulated in Table 5 \& Table 6.

The central pollution control board (CPCB) recommended the sound pressure level (SPL) for different areas as follows:

Data collected from the field at 15 different locations, here the data presented for only two locations.

\section{Results and Discussions}

Using the SPSS software, ANOVA techniques is used to find the variation of SPL among the all location as well as the single location (see Figures 1-4) variation of whole location, and (see Figures 5-8) variation of one location.

The salient points that emanate from this study are:

- The SPL or Leq is higher in the morning period and lesser in mid-day and night time.

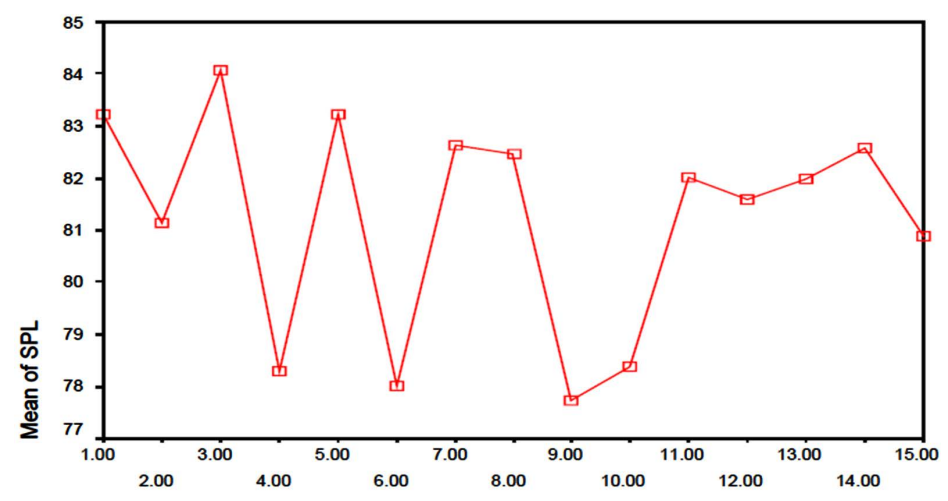

Figure 1. SPL variation along the all location. 
Table 5. Noise estimation of location one.

\begin{tabular}{|c|c|c|c|c|c|c|c|c|c|c|c|c|c|}
\hline \multicolumn{4}{|c|}{ Noise Estimation } & \multicolumn{6}{|c|}{ Location One } & \multicolumn{4}{|c|}{ Date } \\
\hline Time & SPL & Min & $\operatorname{Max}$ & Leq & 31.5 & 63 & 125 & 250 & 500 & $1 \mathrm{k}$ & $2 \mathrm{k}$ & $4 \mathrm{k}$ & $8 \mathrm{k}$ \\
\hline $6.45-6.55$ & 74.8 & 75.5 & 97.3 & 82.8 & 75 & 82.6 & 79.8 & 82.6 & 80.6 & 85 & 75 & 67.5 & 62.9 \\
\hline $6.55-7.05$ & 83 & 76 & 111.6 & 96.3 & 78.8 & 85 & 80.4 & 73 & 77.2 & 69.4 & 72.2 & 64.8 & 68.5 \\
\hline $7.05-7.15$ & 81.4 & 53.7 & 93.8 & 79.4 & 86.1 & 77.9 & 78.4 & 80.4 & 80.9 & 76.4 & 77 & 81.3 & 63.6 \\
\hline $7.15-7.25$ & 80 & 85.2 & 91.9 & 75.4 & 77.6 & 87.5 & 80.2 & 75.9 & 86.7 & 77.9 & 76.9 & 64.8 & 65.1 \\
\hline $7.25-7.35$ & 81 & 56.4 & 101.8 & 82.5 & 80.6 & 88 & 78.8 & 80.2 & 72.8 & 76 & 76.2 & 73.4 & 77.2 \\
\hline $7.35-7.45$ & 82 & 70.2 & 106.9 & 84.4 & 77.8 & 87.6 & 81.5 & 75.1 & 80 & 74.6 & 75 & 74 & 75.6 \\
\hline $7.45-7.55$ & 81 & 74.2 & 97.5 & 83.2 & 73.4 & 78.4 & 79 & 76.4 & 78 & 73.1 & 73.7 & 73.6 & 72 \\
\hline $7.55-8.05$ & 82.4 & 73.8 & 98.8 & 82 & 81.9 & 84.4 & 83.6 & 81.1 & 74.6 & 72.5 & 71.3 & 67.9 & 67.8 \\
\hline $8.05-8.15$ & 80.6 & 77 & 91.1 & 81.6 & 84.2 & 86.1 & 82.6 & 78.2 & 77 & 77.8 & 83.1 & 76.5 & 68.8 \\
\hline $8.15-8.25$ & 83.2 & 76 & 93.2 & 88.5 & 75.8 & 89.8 & 82.2 & 78.3 & 76.8 & 72.9 & 78.9 & 80.8 & 64 \\
\hline $9.00-9.15$ & 78 & 59.9 & 101.2 & 82.4 & 86.7 & 85.9 & 84.5 & 77.4 & 73.9 & 79.2 & 74.3 & 7.9 & 64.5 \\
\hline $9.15-9.30$ & 80.4 & 56.2 & 101.9 & 85.2 & 80.3 & 82.3 & 80.3 & 77.5 & 77.1 & 79.2 & 78.1 & 72.1 & 69.5 \\
\hline $9.30-9.45$ & 83.7 & 56.1 & 103.9 & 83.2 & 82.1 & 86.6 & 80.3 & 75.7 & 88.2 & 79.2 & 74.6 & 66.5 & 54.9 \\
\hline $9.45-10.00$ & 81.3 & 56.3 & 99.9 & 82.9 & 74.5 & 84.4 & 82 & 78 & 82.5 & 79.2 & 73.4 & 56 & 63.3 \\
\hline $10.00-10.15$ & 82.2 & 52.5 & 104 & 82.9 & 81.1 & 85 & 83.3 & 79.3 & 78.4 & 79.2 & 74.5 & 74 & 66.9 \\
\hline $10.15-10.30$ & 83.2 & 53.1 & 105.6 & 83 & 83.4 & 84.2 & 80.2 & 79.3 & 79.2 & 79.2 & 75.5 & 79.2 & 62.8 \\
\hline $10.30-10.45$ & 81.4 & 53.1 & 100.2 & 83.4 & 77.2 & 80.1 & 87.5 & 78.1 & 80 & 79.2 & 73.7 & 67.3 & 66.2 \\
\hline $10.45-11.00$ & 80.6 & 54.6 & 102.2 & 82.7 & 82.4 & 86.8 & 86.4 & 81.3 & 77.6 & 79.2 & 74.9 & 72.3 & 64.6 \\
\hline $11.00-11.15$ & 84.3 & 54.3 & 102.2 & 82.4 & 80.7 & 82.5 & 83.1 & 79.5 & 76.8 & 79.2 & 73.2 & 65.1 & 61.7 \\
\hline $11.15-11.30$ & 82 & 72.3 & 95 & 82.3 & 83.2 & 82.1 & 82.8 & 77.4 & 80.5 & 79.2 & 71.7 & 68.6 & 62.7 \\
\hline $11.30-11.45$ & 83.1 & 54.5 & 98.7 & 81.7 & 78.8 & 82.9 & 81.2 & 76.3 & 75.3 & 79.2 & 81 & 77.7 & 66 \\
\hline $11.45-12.00$ & 80.1 & 53.5 & 106.6 & 82.9 & 88.3 & 86.6 & 80.6 & 76.5 & 77.5 & 79.2 & 75 & 66.6 & 65.7 \\
\hline $12.00-12.15$ & 80.9 & 52.9 & 103.7 & 83 & 89.3 & 90.3 & 89.1 & 81.1 & 79.2 & 79.2 & 72.9 & 79.5 & 65.5 \\
\hline $12.15-12.30$ & 86.9 & 51.3 & 100.1 & 82.7 & 83.5 & 84.9 & 77.8 & 77.7 & 78.1 & 79.2 & 70.7 & 68.9 & 60.9 \\
\hline $12.30-12.45$ & 82.5 & 74.6 & 96 & 83.1 & 85.7 & 81.2 & 79.2 & 77.9 & 75.6 & 85.7 & 66.7 & 68.2 & 64.5 \\
\hline $3.15-3.30$ & 80.6 & 52 & 102.7 & 82.5 & 80.9 & 84.1 & 86.7 & 83.6 & 81.9 & 77.1 & 80.5 & 75.5 & 68.8 \\
\hline $3.30-3.45$ & 82.1 & 50.2 & 101.1 & 83.3 & 93.6 & 85.8 & 89.9 & 86 & 83.4 & 78.5 & 85.4 & 72 & 70.1 \\
\hline $3.45-4.00$ & 85.8 & 50.2 & 101.9 & 83.5 & 91.7 & 85.9 & 86.6 & 81.8 & 84 & 79.6 & 81 & 76.1 & 75.4 \\
\hline $4.00-4.15$ & 90.3 & 71.5 & 106.5 & 83.5 & 92.4 & 89 & 93.1 & 86.8 & 83.9 & 88.2 & 78.1 & 82.9 & 78.1 \\
\hline $4.15-4.30$ & 84.8 & 69.8 & 103.5 & 83.4 & 86.2 & 91.1 & 83.5 & 82.5 & 82.5 & 79.6 & 82.2 & 81.2 & 72.8 \\
\hline $4.30-4.45$ & 85.1 & 60 & 99.2 & 82.5 & 76.9 & 82.3 & 75.9 & 83.7 & 78.8 & 76.5 & 74.6 & 74 & 76.8 \\
\hline $4.45-5.00$ & 85.1 & 55.7 & 107.5 & 84.5 & 80.3 & 86.6 & 87.6 & 80.2 & 83.7 & 77.1 & 83.2 & 70.2 & 67.8 \\
\hline $5.00-5.15$ & 84.6 & 53.4 & 101.6 & 84.1 & 84.1 & 85.7 & 86.8 & 81.2 & 76 & 74.3 & 79.3 & 85.6 & 73 \\
\hline $5.15-5.30$ & 85 & 53.2 & 100.1 & 83.5 & 85.2 & 84.9 & 85.6 & 82.3 & 77.8 & 75.6 & 78.5 & 86 & 74.1 \\
\hline $5.30-5.45$ & 84.6 & 54 & 101.9 & 83.7 & 85.8 & 92.3 & 89 & 79.5 & 80.6 & 78.3 & 78.1 & 87.1 & 72.2 \\
\hline $5.45-6.00$ & 85.5 & 74 & 107.3 & 84.7 & 82.8 & 94.7 & 87 & 79.5 & 84 & 84.6 & 83.7 & 76 & 75.2 \\
\hline $6.00-6.15$ & 86.5 & 72.6 & 101.7 & 82.9 & 79.5 & 89.5 & 83.4 & 78.7 & 77.2 & 75.4 & 70.1 & 82.7 & 72.2 \\
\hline
\end{tabular}


Table 6. Noise estimation of location two.

\begin{tabular}{|c|c|c|c|c|c|c|c|c|c|c|c|c|c|}
\hline \multicolumn{4}{|c|}{ Noise Estimation } & \multicolumn{6}{|c|}{ Location Two } & \multicolumn{4}{|c|}{ Date } \\
\hline Time & SPL & Min & Max & Leq & 31.5 & 63 & 125 & 250 & 500 & $1 \mathrm{k}$ & $2 \mathrm{k}$ & $4 \mathrm{k}$ & $8 \mathrm{k}$ \\
\hline $6.15-6.30$ & 75.5 & 40.1 & 92.8 & 76 & 72.3 & 82.1 & 65.1 & 75.1 & 69.3 & 71.9 & 68.9 & 55.7 & 46.3 \\
\hline $6.30-6.45$ & 77.9 & 62.3 & 95.1 & 78 & 78.4 & 87.7 & 89.4 & 76.7 & 74.8 & 66.5 & 75 & 72.7 & 63 \\
\hline $6.45-7.00$ & 87.4 & 59.9 & 91.5 & 75.9 & 68.3 & 72.3 & 79.6 & 70.5 & 72.9 & 69.1 & 74.4 & 69.6 & 69.4 \\
\hline $7.00-7.15$ & 81.8 & 58.6 & 96.7 & 79.1 & 75.4 & 89.8 & 76.2 & 79.5 & 77.9 & 76.8 & 62.9 & 56.7 & 65.9 \\
\hline $7.15-7.30$ & 82.7 & 63.1 & 96.5 & 78.9 & 80.2 & 83.5 & 80.5 & 83.5 & 72 & 74.9 & 71.7 & 55.2 & 66.5 \\
\hline $7.30-7.45$ & 82.2 & 63.1 & 99.1 & 79.1 & 77.6 & 76.1 & 80.2 & 80.6 & 75.3 & 72.3 & 75.2 & 73 & 63.2 \\
\hline $7.45-8.00$ & 85.8 & 67.9 & 90 & 79 & 77.2 & 82.6 & 80.4 & 80.5 & 84.5 & 78.5 & 76.3 & 77.1 & 69.2 \\
\hline $8.00-8.15$ & 81.2 & 55 & 99.4 & 78.9 & 83.3 & 79.9 & 83.3 & 84.2 & 84.2 & 73.7 & 75.5 & 71.5 & 75.1 \\
\hline $8.15-8.30$ & 80.1 & 68 & 96.6 & 79.1 & 74.4 & 78.6 & 77.6 & 79.8 & 75.5 & 71.6 & 74.2 & 67.6 & 67.4 \\
\hline $8.30-8.45$ & 82.3 & 51 & 98.1 & 80.5 & 84.4 & 99.1 & 87.2 & 80.6 & 70,1 & 76.8 & 77 & 88.4 & 72.7 \\
\hline $8.45-9.00$ & 85.5 & 56 & 103 & 80.9 & 74.4 & 78.5 & 88.5 & 80.8 & 85.4 & 87.9 & 87 & 78.4 & 74.9 \\
\hline 9.15 - 9.30 & 81.9 & 51.2 & 92.1 & 78.5 & 85.7 & 84.5 & 80.3 & 83.3 & 82.6 & 70.4 & 75.3 & 73.9 & 66.4 \\
\hline $9.30-9.45$ & 84.9 & 52 & 92.3 & 78.9 & 78.8 & 81.5 & 86.7 & 86.6 & 79.1 & 79.2 & 77.4 & 67.8 & 66.8 \\
\hline $9.45-10.00$ & 83.9 & 52 & 97.6 & 78.5 & 83.4 & 83.9 & 81.2 & 77.1 & 80.4 & 75.3 & 70.7 & 70.3 & 55.7 \\
\hline $10.00-10.15$ & 77.3 & 68.8 & 97.6 & 78.9 & 77 & 84.4 & 81.2 & 74.4 & 74.4 & 78.3 & 82 & 73.2 & 66.1 \\
\hline $10.15-10.30$ & 80.6 & 53.1 & 96.9 & 78 & 80.4 & 83.4 & 82.1 & 83.4 & 78.9 & 70.4 & 71 & 70.9 & 66.5 \\
\hline $10.30-10.45$ & 80.4 & 52 & 97.1 & 79.1 & 82.3 & 79 & 84.6 & 79.1 & 78 & 79 & 76.1 & 69.3 & 65.4 \\
\hline $10.45-11.00$ & 78.4 & 68.6 & 87.9 & 77.51 & 75.4 & 83.2 & 85 & 86.2 & 77 & 75.6 & 74.8 & 68.6 & 67.3 \\
\hline $11.00-11.15$ & 77.2 & 69 & 95.6 & 79.9 & 80 & 84.7 & 89.2 & 76.2 & 75.1 & 74.7 & 69.9 & 64.5 & 67.6 \\
\hline 11.15 - 11.30 & 80.4 & 67.1 & 88.6 & 77.4 & 74.5 & 83.6 & 80.2 & 81.3 & 81.4 & 77.3 & 74.7 & 68.4 & 72.1 \\
\hline $11.30-11.45$ & 80.3 & 56.4 & 101.2 & 78.7 & 78.8 & 80.2 & 82.1 & 84.9 & 83.3 & 75.2 & 70.4 & 74 & 67.2 \\
\hline $11.45-12.00$ & 82.3 & 66.4 & 88.1 & 76.9 & 78 & 73.7 & 84.3 & 83.6 & 72.4 & 73.8 & 75.5 & 67.5 & 56.4 \\
\hline $2.45-3.00$ & 83.4 & 62.2 & 100.2 & 78.3 & 85.8 & 89.6 & 76.1 & 79.4 & 74.8 & 77.5 & 73.9 & 78 & 62.4 \\
\hline $3.00-3.15$ & 84.6 & 63.1 & 103 & 78.4 & 75.1 & 83.3 & 83.6 & 79.2 & 81.7 & 72.5 & 74 & 78.1 & 61.1 \\
\hline $3.15-3.30$ & 79.2 & 68.2 & 84.5 & 76.7 & 76.9 & 91.1 & 84.7 & 74.5 & 80.7 & 70.7 & 70.7 & 66.4 & 60.1 \\
\hline $3.30-3.45$ & 77.6 & 67.2 & 107 & 79.7 & 76.5 & 82.3 & 84.8 & 80.7 & 97.1 & 74.1 & 80.3 & 70.7 & 57.3 \\
\hline $3.45-4.00$ & 75.2 & 64.7 & 91.9 & 78.7 & 75 & 83 & 83.2 & 82 & 80.4 & 70.3 & 71.2 & 66.7 & 61.8 \\
\hline $4.00-4.15$ & 80.9 & 63.5 & 95.9 & 77.7 & 71.9 & 75.7 & 78.9 & 76.4 & 81.3 & 74.4 & 72 & 68 & 62.8 \\
\hline $4.15-4.30$ & 82.6 & 63.4 & 103.9 & 79.5 & 79.9 & 76.9 & 81.6 & 79.2 & 82.2 & 77.6 & 71.2 & 65.7 & 63.3 \\
\hline $4.30-4.45$ & 81.1 & 68.7 & 86.7 & 80.3 & 75.7 & 79 & 86.2 & 80.5 & 74.6 & 82.2 & 66.6 & 77.7 & 70.9 \\
\hline $4.45-5.00$ & 71.7 & 54 & 101.9 & 79.4 & 83.3 & 85.1 & 82.3 & 83.6 & 81.2 & 70.6 & 80.7 & 69.5 & 62.8 \\
\hline $5.00-5.15$ & 76.4 & 65.8 & 94.3 & 78.4 & 75.5 & 73 & 74.4 & 76.2 & 81.6 & 71.7 & 72.3 & 56.9 & 75 \\
\hline $5.15-5.30$ & 81.5 & 63.5 & 94.9 & 78.2 & 76.4 & 88.5 & 80.5 & 86 & 87.2 & 83.4 & 71.7 & 78.6 & 64.2 \\
\hline $5.30-5.45$ & 81.4 & 68.5 & 88.7 & 78.3 & 87 & 81.5 & 81.3 & 79.5 & 78.8 & 75.9 & 80.2 & 70.1 & 70.3 \\
\hline $5.45-6.00$ & 82.3 & 50.4 & 94.7 & 78.2 & 80.5 & 83.1 & 78.3 & 85.9 & 80.5 & 75.7 & 70.6 & 83.5 & 78.5 \\
\hline $6.00-6.15$ & 84.3 & 67.9 & 92.3 & 78.9 & 82.7 & 84.1 & 83.5 & 81.6 & 84.5 & 75 & 71.1 & 83.3 & 69.9 \\
\hline $6.15-6.30$ & 80.3 & 53.6 & 96.2 & 78.5 & 82.7 & 82.8 & 80.6 & 76 & 80.7 & 72.4 & 70.3 & 66 & 68.4 \\
\hline $6.30-6.45$ & 82.4 & 69.4 & 99.9 & 80.8 & 80 & 83.6 & 87.4 & 83.2 & 79.4 & 84.2 & 78.8 & 72 & 65.8 \\
\hline $6.45-7.00$ & 89.1 & 67.4 & 94 & 79.2 & 87.5 & 86.3 & 87.6 & 78.3 & 78.7 & 76.9 & 72 & 75.3 & 74.7 \\
\hline
\end{tabular}




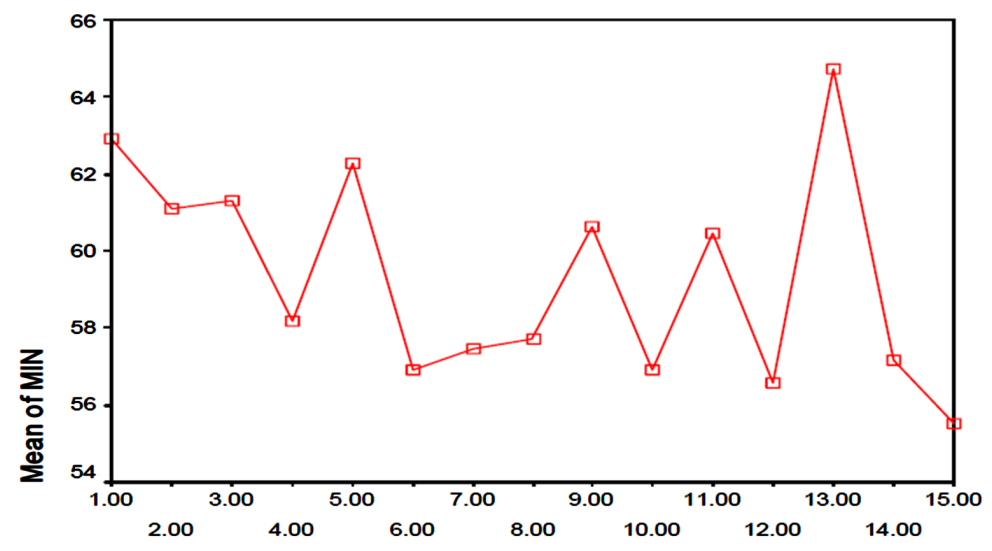

Figure 2. Min. of SPL variation along the all location.

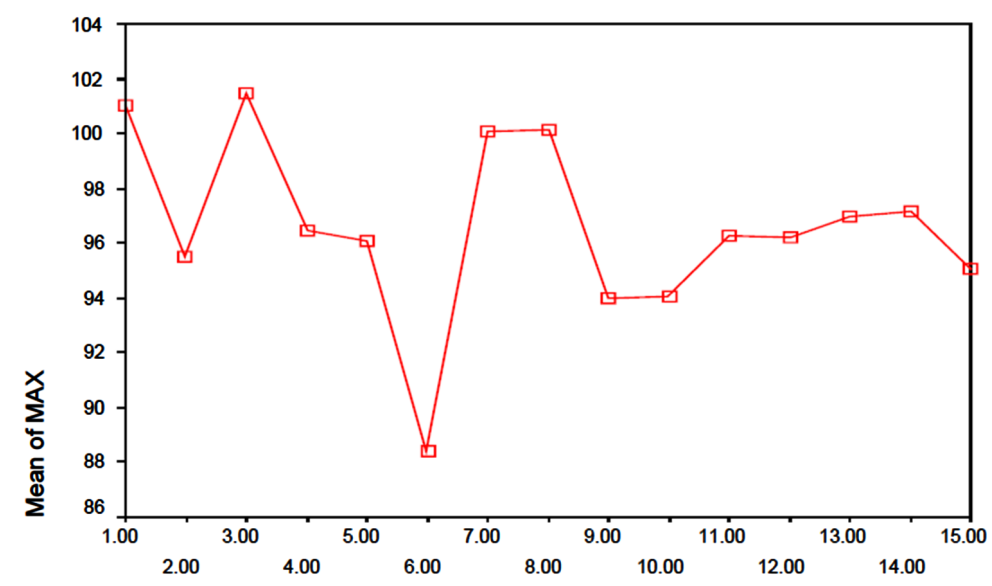

Figure 3. Max. of SPL variation along the all locations.

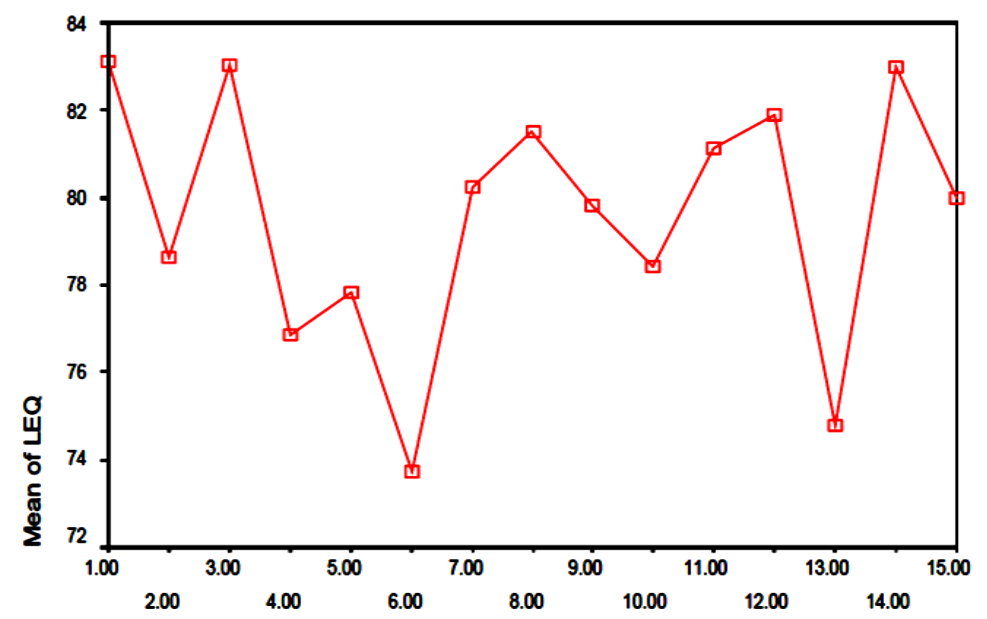

Figure 4. Leq of SPL variation along the all.

- The SPL or Leq is not same level for the all observation points.

- See the Table 7 and Table 8; the significance values are not same for all the location.

- If the significance value is less than 0.05 , it is unacceptable variation of SPL.

- ANOVA test shows that the levels are not significant. 
Table 7. One way ANOVA: Variation along the all location.

\begin{tabular}{|c|c|c|c|c|c|c|}
\hline & ANOVA Results & Sun of Squares & $\mathrm{df}$ & Mean Square & $\mathrm{F}$ & Sig. \\
\hline \multirow{3}{*}{ SPL } & Between Groups & 2498.488 & 14 & 178.468 & & \multirow{3}{*}{0.000} \\
\hline & Within Groups & 6337.465 & 606 & 10.458 & \multirow{2}{*}{17.065} & \\
\hline & Total & 8835.953 & 620 & - & & \\
\hline \multirow{3}{*}{ MIN } & Between Groups & 4558.174 & 14 & 325.584 & \multirow{3}{*}{4.792} & \multirow{3}{*}{0.000} \\
\hline & Within Groups & 41174.185 & 606 & 67.944 & & \\
\hline & Total & 45732.358 & 620 & - & & \\
\hline \multirow{3}{*}{ MAX } & Between Groups & 6224.405 & 14 & 444.600 & \multirow{3}{*}{18.736} & \multirow{3}{*}{.000} \\
\hline & Within Groups & 14380.487 & 606 & 23.730 & & \\
\hline & Total & 20604.892 & 620 & - & & \\
\hline \multirow{3}{*}{ LEQ } & Between Groups & 4867.386 & 14 & 347.670 & \multirow{3}{*}{25.652} & \multirow{3}{*}{0.000} \\
\hline & Within Groups & 8213.178 & 606 & 13.553 & & \\
\hline & Total & 13080.564 & 620 & - & & \\
\hline \multirow{3}{*}{ F31.5 } & Between Groups & 19793.499 & 14 & 1413.821 & \multirow{3}{*}{1.359} & \multirow{3}{*}{0.168} \\
\hline & Within Groups & 630581.1 & 606 & 1040.563 & & \\
\hline & Total & 650374.6 & 620 & - & & \\
\hline \multirow{3}{*}{ F63 } & Between Groups & 4448.501 & 14 & 317.750 & \multirow{3}{*}{21.734} & \multirow{3}{*}{0.000} \\
\hline & Within Groups & 8844.980 & 605 & 14.620 & & \\
\hline & Total & 13293.481 & 619 & - & & \\
\hline \multirow{3}{*}{ F125 } & Between Groups & 3975.179 & 14 & 283.941 & \multirow{3}{*}{17.948} & \multirow{3}{*}{0.000} \\
\hline & Within Groups & 9586.940 & 606 & 15.820 & & \\
\hline & Total & 13562.119 & 620 & - & & \\
\hline \multirow{3}{*}{ F250 } & Between Groups & 4377.614 & 14 & 312.687 & \multirow{3}{*}{23.137} & \multirow{3}{*}{0.000} \\
\hline & Within Groups & 8189.754 & 606 & 13.514 & & \\
\hline & Total & 12567.368 & 620 & - & & \\
\hline \multirow{3}{*}{ F500 } & Between Groups & 4235.510 & 14 & 302.536 & \multirow{3}{*}{22.787} & \\
\hline & Within Groups & 8045.828 & 606 & 13.277 & & 0.000 \\
\hline & Total & 12281.337 & 620 & - & & \\
\hline & Between Groups & 3796.799 & 14 & 271.200 & & \\
\hline $1 \mathrm{~K}$ & Within Groups & 11134.173 & 603 & 18.465 & 14.688 & 0.000 \\
\hline & Total & 14930.972 & 617 & - & & \\
\hline & Between Groups & 11688.107 & 14 & 834.865 & & \\
\hline $2 \mathrm{~K}$ & Within Groups & 436791.8 & 604 & 723.165 & 1.154 & בחم \\
\hline & Total & 448479.9 & 618 & - & & 0.007 \\
\hline & Between Groups & 13853.055 & 14 & 989.504 & & \\
\hline $4 \mathrm{~K}$ & Within Groups & 439115.3 & 604 & 727.012 & 1.361 & 0.167 \\
\hline & Total & 452968.3 & 618 & - & & \\
\hline & Between Groups & 11730.581 & 14 & 837.899 & & \\
\hline $8 \mathrm{~K}$ & Within Groups & 452994.5 & 605 & 748.751 & 1.119 & 0.337 \\
\hline & Total & 464725.1 & 619 & - & & \\
\hline
\end{tabular}


Table 8. One way ANOVA (second type): Variation along the single location.

\begin{tabular}{|c|c|c|c|c|c|c|}
\hline & ANOVA Results & Sun of Squares & df & Mean Square & F & Sig. \\
\hline \multirow{3}{*}{ SPL } & Between Groups & 171.007 & 3 & 57.002 & & \multirow{3}{*}{0.000} \\
\hline & Within Groups & 225.856 & 40 & 5.646 & \multirow{2}{*}{10.095} & \\
\hline & Total & 396.863 & 43 & - & & \\
\hline \multirow{3}{*}{ MIN } & Between Groups & 909.064 & 3 & 303..021 & \multirow{3}{*}{3.341} & \multirow{3}{*}{0.029} \\
\hline & Within Groups & 3627.516 & 40 & 90.688 & & \\
\hline & Total & 4536.580 & 43 & - & & \\
\hline \multirow{3}{*}{ MAX } & Between Groups & 75.498 & 3 & 25.166 & \multirow{3}{*}{1.418} & \multirow{3}{*}{0.252} \\
\hline & Within Groups & 710.098 & 40 & 17.752 & & \\
\hline & Total & 785.595 & 43 & - & & \\
\hline \multirow{3}{*}{ LEQ } & Between Groups & 3.624 & 3 & 1.208 & \multirow{3}{*}{.158} & \multirow{3}{*}{0.924} \\
\hline & Within Groups & 305.995 & 40 & 7.650 & & \\
\hline & Total & 309.619 & 43 & - & & \\
\hline \multirow{3}{*}{ F31.5 } & Between Groups & 239.867 & 3 & 79.956 & \multirow{3}{*}{4.520} & \multirow{3}{*}{0.008} \\
\hline & Within Groups & 707.565 & 40 & 17.689 & & \\
\hline & Total & 947.432 & 43 & - & & \\
\hline \multirow{3}{*}{ F63 } & Between Groups & 125.241 & 3 & 41.747 & \multirow{3}{*}{3.727} & \multirow{3}{*}{0.019} \\
\hline & Within Groups & 448.058 & 40 & 11.201 & & \\
\hline & Total & 573.299 & 43 & - & & \\
\hline \multirow{3}{*}{ F125 } & Between Groups & 252.204 & 3 & 84.068 & \multirow{3}{*}{8.712} & \multirow{3}{*}{0.000} \\
\hline & Within Groups & 386.002 & 40 & 9.650 & & \\
\hline & Total & 638.206 & 43 & - & & \\
\hline \multirow{3}{*}{ F250 } & Between Groups & 193.861 & 3 & 64.620 & \multirow{3}{*}{11.351} & \multirow{3}{*}{0.000} \\
\hline & Within Groups & 227.716 & 40 & 5.693 & & \\
\hline & Total & 421.577 & 43 & - & & \\
\hline \multirow{3}{*}{ F500 } & Between Groups & 97.975 & 3 & 32.658 & \multirow{3}{*}{3.482} & \\
\hline & Within Groups & 375.217 & 40 & 9.380 & & 0.025 \\
\hline & Total & 473.192 & 43 & - & & \\
\hline & Between Groups & 75.850 & 3 & 25.283 & & \\
\hline $1 \mathrm{~K}$ & Within Groups & 481.447 & 40 & 12.036 & 2.101 & 0.115 \\
\hline & Total & 557.296 & 43 & - & & \\
\hline & Between Groups & 673.632 & 3 & 224.544 & & \\
\hline $2 \mathrm{~K}$ & Within Groups & 4836.450 & 40 & 120.911 & 1.857 & 2015? \\
\hline & Total & 5510.082 & 43 & - & & 0.152 \\
\hline & Between Groups & 1320.861 & 3 & 440.287 & & \\
\hline $4 \mathrm{~K}$ & Within Groups & 1352.695 & 40 & 33.817 & 13.020 & 0.000 \\
\hline & Total & 2673.556 & 43 & - & & \\
\hline & Between Groups & 646.639 & 3 & 215.546 & & \\
\hline $8 \mathrm{~K}$ & Within Groups & 738.564 & 40 & 18.464 & 11.674 & 0.000 \\
\hline & Total & 1385.203 & 43 & - & & \\
\hline
\end{tabular}




\section{Conclusions}

The urban noise surveys have been conducted at 15 locations and maximum and minimum noise level are shown in the Figure 9.

1) The peak early morning max levels observed are $107,105 \mathrm{~dB}(\mathrm{~A})$, which are very much on the higher side.

2) In some places the noise levels in the afternoon times are very high.

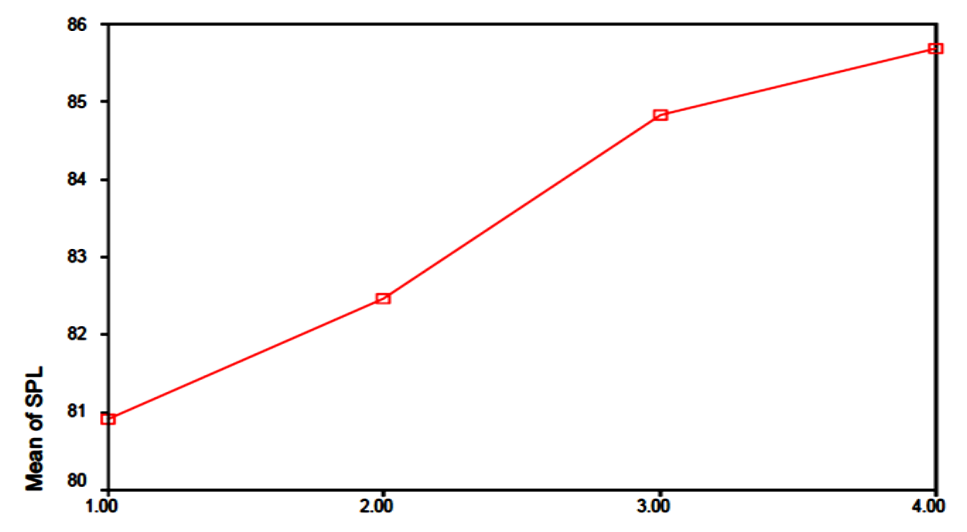

Figure 5. SPL variation along the one location.

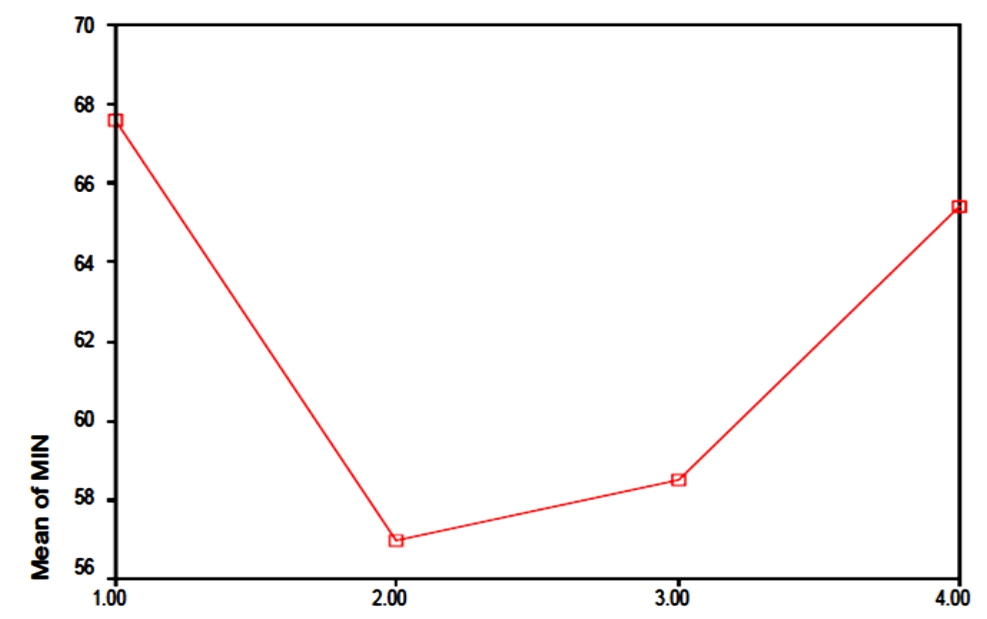

Figure 6. Min of SPL variation along the one location.

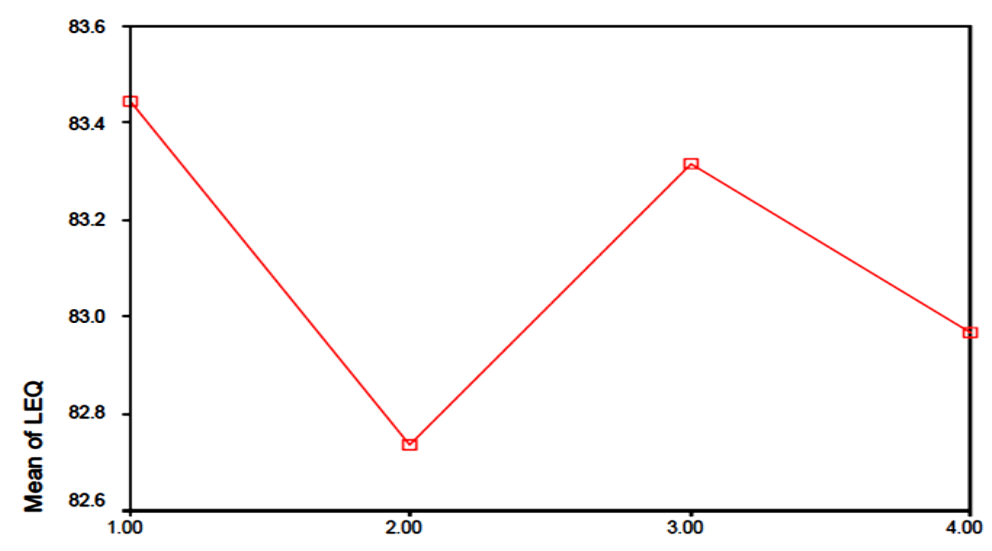

Figure 7. Max of SPL variation along the one location. 
3) However in certain places two levels are minimum especially in the early morning hours ( $<30 \mathrm{~dB}(\mathrm{~A})$ ).

4) In most of the places the low frequency noise predominates especially at $31.5 \mathrm{~Hz}, 63 \mathrm{~Hz}$ octave. $\mathrm{dB}$.

5) Figure 9 shows the Leq levels to be between 77 to $99.7 \mathrm{~dB}(\mathrm{~A})$ at times it is even recorded as high as 118

6) The minimum recorded, $\mathrm{dB}(\mathrm{A})$ is around $50 \mathrm{~dB}(\mathrm{~A})$, as per the central pollution control board (CPCB) recommended the sound pressure level (SPL) for different areas (Table 9). Noise levels are significant between and within groups (Table 7 and Table 8). The variations of sound Pressure (Max, Min and Leq) levels are shown in (Figure 9). The max and Leq levels exceed the recommended noise levels.

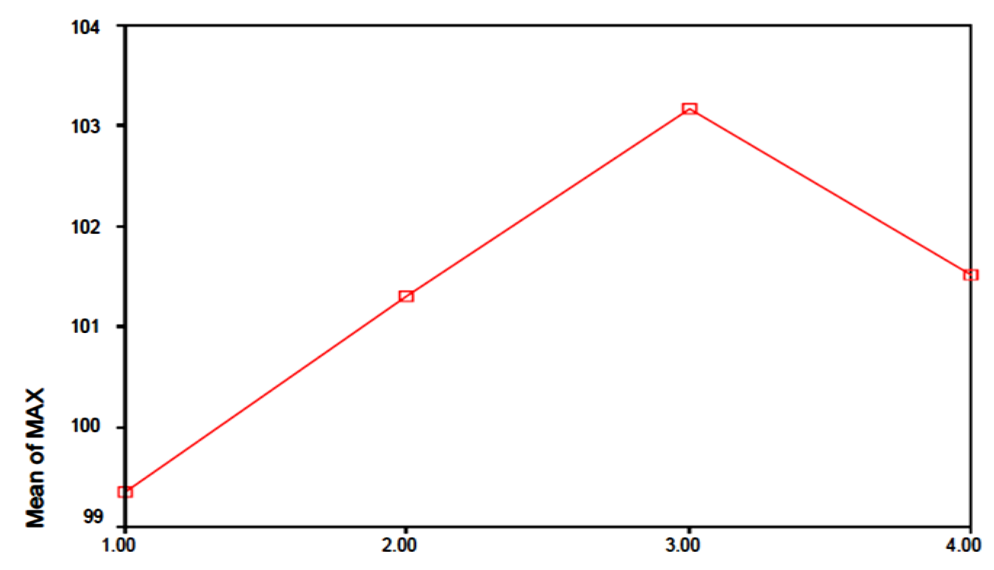

Figure 8. Leq of SPL variation along the one location.

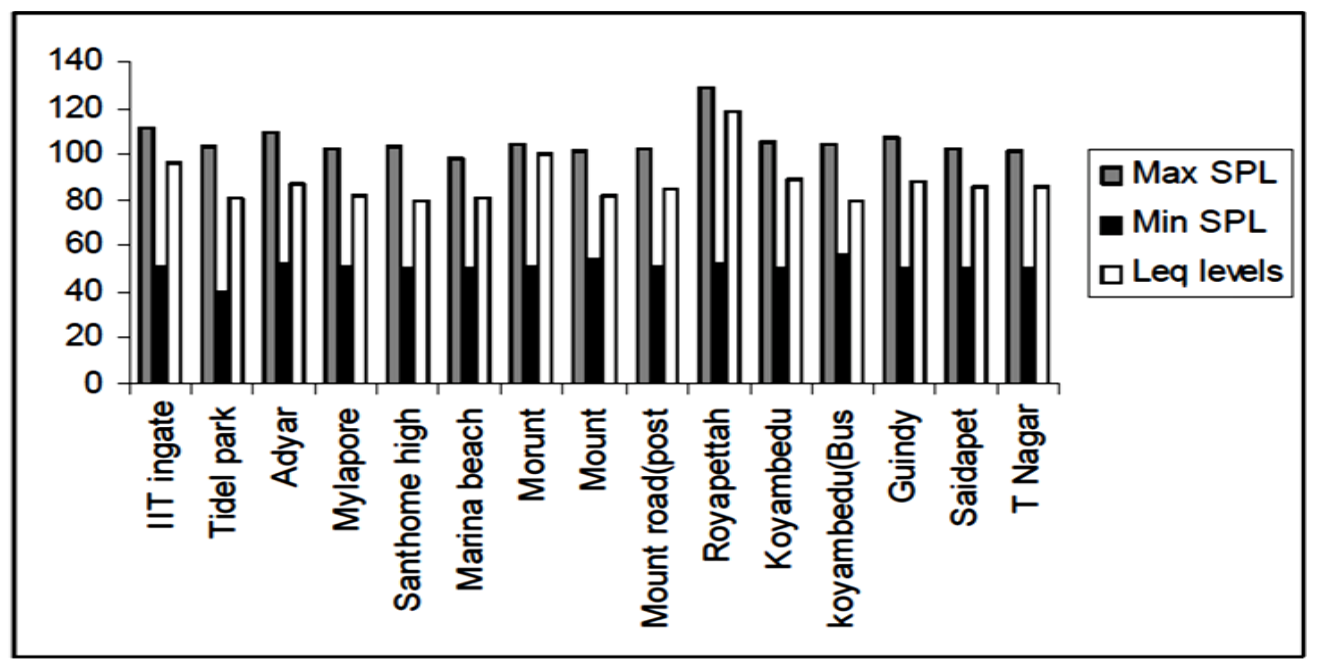

Figure 9. Variation of SPL along the whole locations.

Table 9. Central pollution control board recommendation for noise level.

\begin{tabular}{cccc}
\hline & & & SPL Leq (dBA) \\
S. No. & Area & Day Time & Night Time \\
\cline { 3 - 4 } & & 75 & 70 \\
2 & Industrial & 65 & 60 \\
3 & Commercial & 55 & 50 \\
4 & Residential & 50 & 40 \\
\hline
\end{tabular}




\section{Acknowledgements}

The authors express their profound thanks to Dr. Koya Purnachandra Rao, Professor, Hawassa University for his critical reading and suggestions.

\section{References}

[1] Crocker, M.J. (1998) Handbook of Acoustic. John Wiley and Sons, New York.

[2] Harris, C.M. (1994) Noise Control in Building. McGraw-Hill, New York.

[3] Beranek, L.L. (1992) Noise and Vibration Control Engineering. John Wiley and Sons, New York.

[4] Harris, M. (1957) Handbook of Noise Control. McGraw Hill, New York.

[5] Day, B.F., Ford, R.D. and Lord, P. (1994) Building Acoustic. Elsevier Publishing Company Ltd., Amsterdam.

[6] Kinsler, L.E. and Frey, A.R. (1991) Fundamentals of Acoustic. John Wiley and Sons, New York.

[7] Walker, J.G., et al. (1995) An Investigation of Noise from Train on Bridge. Journal of Sound and Vibration, 193, 307314. http://dx.doi.org/10.1006/jsvi.1996.0271

[8] Skinner, C.J. and Grimwood, C.J. (2005) Population Exposure and Attitudes to Environmental Noise. Journal of Applied Acoustic, 66, 231-243. http://dx.doi.org/10.1016/j.apacoust.2004.07.009

[9] Nooralahiyan, A.Y. and Kirby, H.R. (1998) Vehicle Classification by Acoustic Signature. Journal of Applied Acoustic, 27, 205-214.

[10] Thorsson, P.J. (2004) Macroscopic Modeling of Urban Traffic Noise-Influence of Absorption \& Vehicle Flow Distribution. Journal of Applied Acoustic, 66, 195-209. http://dx.doi.org/10.1016/j.apacoust.2004.07.013

[11] Pandya, G.H. (1999) Urban Noise: A Need of Acoustic Planning. National Environmental Engineering, Research Institute, Nagpur.

[12] Gökdağ, M., et al. (2005) A Traffic Noise Prediction Method Based on Vehicle Composition Using Genetic Algorithms. Applied Acoustics, 66, 799-809.

[13] Tansatchs, M., Pamanikabud, P., Brown, A.L. and Affum, J.K. (2005) Motorway Noise Modeling Based on Perpendicular Propagation Analysis of Traffic Noise. Applied Acoustic, 66, 1135-1150. http://dx.doi.org/10.1016/j.apacoust.2005.02.002

[14] Agard, F.C. (2004) On the Use of Perforations to Improve the Sound Absorption of Porous Materials. Applied Acoustic, 66, 625-651.

[15] Fitzgerald, B.M. (1996) The Development and Implementation on Noise Control Measures on an Urban Railway. Journal of Sound and Vibration, 193, 377-385. http://dx.doi.org/10.1006/jsvi.1996.0278

[16] Picaut, J. (2005) Experimental Study of Sound Propagation in a Street. Applied Acoustic, 66, 149-173. http://dx.doi.org/10.1016/j.apacoust.2004.07.014

[17] Moore, J.E. (1966) Design for Noise Reduction. Architectural Press, London. 
Scientific Research Publishing (SCIRP) is one of the largest Open Access journal publishers. It is currently publishing more than 200 open access, online, peer-reviewed journals covering a wide range of academic disciplines. SCIRP serves the worldwide academic communities and contributes to the progress and application of science with its publication.

Other selected journals from SCIRP are listed as below. Submit your manuscript to us via either submit@scirp.org or Online Submission Portal.
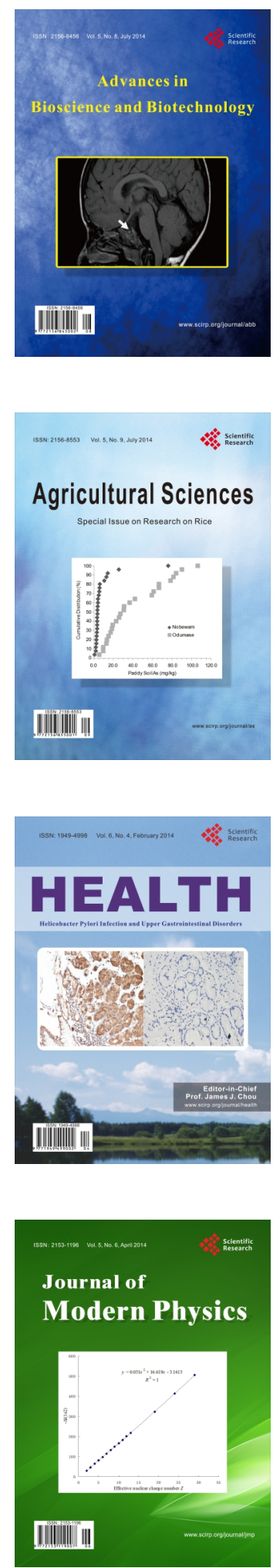
